\title{
La recreación, una perspectiva histórica social
}

\author{
Recreation, a socio-historical perspective
}

Juan Manuel Carreño Cardozo*

\section{Resumen}

Estearticulo presenta una reflexión acerca de cómo influye la historia en la construcción social del conocimiento, entendiendo ésta no como la ciencia del pasado, sino como la relación de causas con la situación del hombre en el tiempo (Marc Bloch, 2001). El escrito se alejará de los esfuerzos por establecer verdades objetivas para dar pie a la reinterpretación de la historia como fundadora de la comprensión de hechos de nuestra cultura, a través de los significados, los sentidos y las sensaciones. Describe algunas aproximaciones para la construcción del conocimiento en recreación, a partir de las cuales se presentan diferencias con la propuesta de la educación fisica en su estructura general, que la ha constituido disciplinarmente, situando los orígenes de ambas en referentes distanciados epistemológicamente. El proceso se sustenta en la perspectiva histórica social, la cual describe la cultura y el lenguaje en el marco de la intersubjetividad como formas de construcción social del conocimiento.

Palabras clave: Construcción social del conocimiento, educacion fisica, perspectiva historico social, recreacion.

\section{Abstract}

Fecha de recepción: 13 de mayo de 2005.

Fecha de aceptación: 22 de septiembre de 2005.

This article presents a reflection about how the history has influenced in the social construction of knowledge, from understanding the history as the relation of causes with the human being situation in time (Marc Bloch, 2001), without understanding the history as the science of the past time. This article goes away from the efforts for establishing objective truths and promotes the re-interpretation of the comprehension of facts produced by our culture by means of the meanings, senses and feelings. It describes some approximations to the construction of knowledge in recreation. From these approximations, several differences have arisen with the proposal of the physical education in its general structure in which it has made up as a discipline of knowledge. The origins of both the recreation and physical education are placed in different points separated epistemologically. The process is supported in the socio-historical perspective, which it describes the culture and language in the inter-subjective as forms of social construction of knowledge.

Key words: $\quad$ Social construction of knowledge, physical education, sociohistorical perspective, recreation.

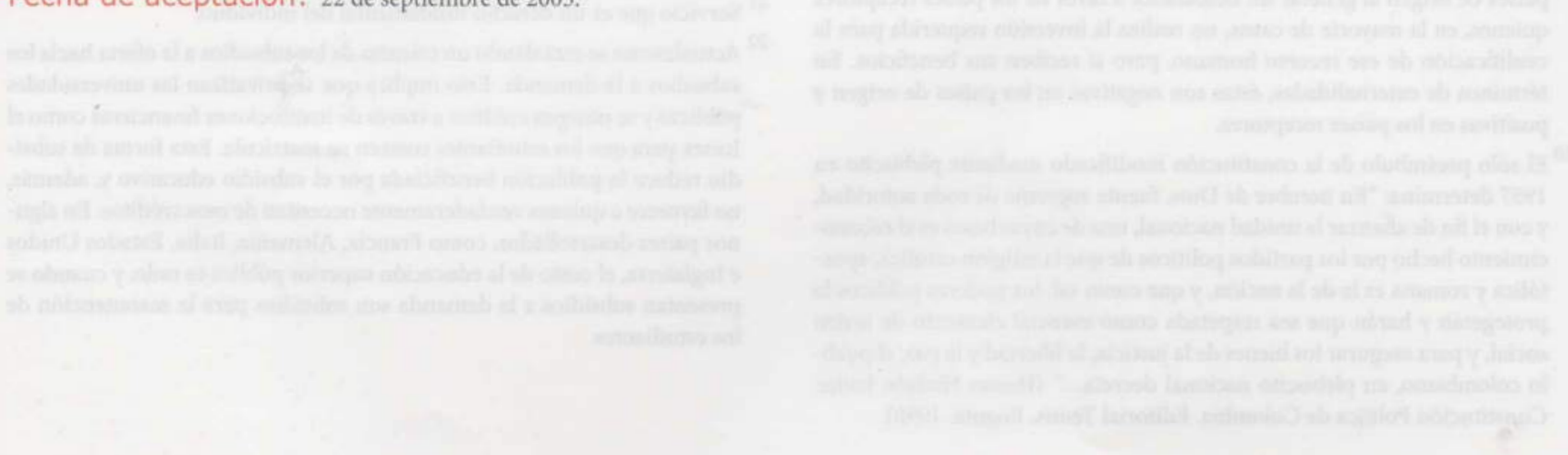

* Licenciado en Educación Física y Especialista en Teorías, Métodos y Técnicas de Investigación Social, Universidad Pedagógica Nacional, aspirante a Magister en Investigación Social Interdisciplinaria, Universidad Distrital Francisco José de Caldas. Profesor catedrático asistente, Universidad Pedagógica Nacional. 


\section{Las ciencias y el surgimiento de la} cultura

Antes de enfocarnos en los problemas particulares de la educación física y la recreación, es necesario exponer las diferencias fundamentales entre la validez que otorga la construcción de las leyes universales de la ciencia natural y la comprensión de la cultura planteada en las ciencias sociales, por cuanto la recreación retoma tendencias de esta última en contraposición a la forma en que la educación física, en su origen, ha asumido elementos de la primera.

Es bien conocida la discusión entre las ciencias naturales y las ciencias sociales en los términos habituales en que las primeras tienden a la explicación de fenómenos naturales, mientras las segundas intentan explicar al humano y su situación compleja. Más allá de dicha diferenciación, podemos reconocer que en el mismo ámbito de las ciencias humanas se ha abierto una brecha entre la comprensión y la interpretación de las culturas, y el conocimiento que otorga validez a través de la experimentación, retomando elementos de las ciencias naturales.

Así, la tendencia positivista en las ciencias humanas apela a la consecución de la verdad a través de lo verificable, teniendo en cuenta la imposibilidad de aislarnos de nuestro propio conocimiento para compararlo con la realidad. Entonces, se intentan verificar hipótesis con hechos para obtener la verdad. A este método se le denomina inductivo. En contraposición, Popper propone que no puede comprobarse la universalidad ni la necesidad por la observación de algunos casos. Por ejemplo, a pesar de que a muchos niños se les mida su capacidad orgánica, siempre existe la posibilidad lógica (y de hecho se presenta) de que no se cumplan promedios establecidos para otros niños; llevándolo al ejemplo kantiano: a pesar de que se observen muchos patos blancos, no es posible afirmar que no existen los patos negros.

Así como en las ciencias naturales, las ciencias humanas para reclamarse como tales apelan al intento de universalidad de sus postulados; de esta forma, podemos nombrar algunas fases que se han presentado respecto a las concepciones de la verdad en la ciencia:

El verificacionismo, descrito por el Círculo de Viena, propone una verdad probable.

El falsacionismo, que habla de la verdad indemostrable y sólo validada en la medida en que describe y permite su falsación.

El falibilismo, que empieza a hablar de una verdad en construcción y tiene que ver con procesos históricos, y
El convencionalismo, de Khun, que propone la verdad dada por un consenso. Esto involucra no sólo procesos históricos, sino de construcción social, y la extracción de la ciencia como elemento neutro y fundamentalmente relacionada con problemas de poder. A partir de aquí se presentan diversas tendencias como crítica al positivismo que, en términos generales, presentan a la ciencia a partir de un punto de vista ideológico y plantean los problemas de comunicación (Habermas), lenguaje y sentido.

Con base en lo anterior, podemos afirmar que la construcción de conocimiento ha vinculado procesos sociales que van desde la concepción de una verdad independiente del sujeto hacia la interrelación entre los argumentos científicos y la historicidad del hombre en su cultura. Para el caso de la educación física, observamos la forma en que las ciencias naturales brindaron una serie de fundamentos que construyeron el discurso fisiológico, médico y pedagógico sin tener en cuenta la historia del sujeto, llegando al punto en que no da cuenta de la cultura y sus transformaciones, por lo que, posteriormente, dirige su mirada hacia planteamientos de disciplinas propias de las ciencias sociales, como la antropología y la sociología, intercambiando saberes y prácticas venidas de una y otra tendencia.

- Podemos hablar, entonces, de la recreación en tanto no se construye en su génesis a partir del discurso positivista de las ciencias naturales, sino que opta por la búsqueda de la comprensión de los discursos sociales; en otras palabras, se aleja del dato y de cualquier verdad que intente ser homogénea y generalizable para reconocer al hombre y sus representaciones inmerso en una cultura sujeta a una historia y a sus transformaciones.

Desde mi punto de vista, la recreación retoma elementos de la corriente idealista al construir el estudio sobre la cultura con un carácter particular y relativo, es decir, defendiendo las características de los grupos humanos a partir de los contextos que le son propios y alejándose definitivamente del estructuralismo, cuya pretensión continúa siendo la obtención de leyes universales. Así pues, la tendencia culturalista no prescinde del sujeto y dice también que se debe constituir un discurso sobre la representación de quien hace ciencia, es decir, discutir el problema del sujeto y el método, otorgándole primordial relevancia al problema del lenguaje.

En conclusión, la recreación busca su saber en la interpretación de las culturas, anteponiendo el discurso sobre diversidad, identidad, sociedad, entre otros, y atendiendo a la discusión sobre el lenguaje como forma de interlocución. 


\section{Reflexión acerca de los discursos que fundamentan la educación física y la recreación}

A continuación describiré algunos referentes que, en el ámbito epistemológico histórico, diferencian la propuesta de la recreación de la tendencia tradicional y generalizada de la educación física. Con este propósito se alude al concepto de salud y de cuerpo como elementos en los cuales se fundamenta un capítulo importante en el nacimiento de la educación física, retomándola en su discurso general ${ }^{1}$.

En primer término, podemos afirmar que buena parte de las prácticas que conforman procesos para el mejoramiento de la salud provienen de la investigación de la fisiología y del discurso médico. Por lo general, se puede tomar el mejoramiento orgánico como alejado de los procesos sociales; sin embargo, cuando se confronta históricamente la producción de verdades, que en lo cotidiano no se prueban ni se discuten, se devela el problema de hábitos involucrados con la relación de poder de un tipo de estado. (Confrontar, por supuesto, a Foucault, Bourdieu, Turner, Chomsky y otros tantos).

De forma un poco más general, todo el discurso orgánico está estructurado sobre el mismo problema del dualismo cartesiano cuerpo-mente. El cuerpo que ha construido nuestras prácticas tradicionales en educación física está estructurado para reproducir y habituar los modelos de un sistema político y económico. Ella misma se ha encargado de definir la división entre experiencia y reflexión de forma que prime la conciencia y el desarrollo definido como mental, sobre los procesos sensibles y de experiencia de mundo, al punto que se favorece una manipulación de las costumbres al servicio del consumo y el produccionismo económico.

Uno de los problemas fundamentales es la condición de familiaridad de los elementos que trabaja la educación física, es decir, se retoman conceptos como salud, deporte, formación, etc., de manera neutra y mecánica, como si no tuvieran que ver con procesos sociales históricos y, por ende, no acarrearan consecuencias dentro de la estructura de la sociedad. Por ejemplo, la noción de cuerpo que sustenta nuestras prácticas tradicionales es fundamentalmente venida del conocimiento eurocéntrico de la ciencia: de griegos, romanos, franceses y sus disciplinas. También con sus formas de construcción, problemas y perversiones.

Además, ha primado el conocimiento construido de las culturas dominantes, relegando otras fuentes de sa- ber de la misma forma que en el proyecto civilizador del descubrimiento, es decir, la construcción de conocimiento no atiende fácilmente a saberes diversos y se establece, en gran medida, por las verdades homogenizadoras y dominantes.

Sin embargo, nuestra historia y nuestras raíces no se remontan exclusivamente las invasiones inglesas, españolas y francesas, sino que atraviesan muchos siglos de una producción diversa de conocimiento en nuestros orígenes. Para algunos de nosotros este hecho hace particularmente diversas nuestras culturas y sus formas de expresión, distanciándolas de manera notable de las tradiciones propias de otros países.

La pregunta es frecuente: ¿dónde está la otra parte de nuestra historia? El descarte sistemático y radical de los contextos diversos al del origen eurocéntrico tiene varias interpretaciones, pero, sobre todo, se trata de la imposición argumentada de una lógica que, para efectos de la dominación, busca dar una única oportunidad de conocimiento y de experiencia de mundo, y que niega la posibilidad de otras lógicas diferentes de la racional de Occidente.

Esta negación de la otra historia se refiere a sus características anacrónicas y ahistóricas que desdibujan el tiempo lineal y los hechos fuera de una trascendencia colectiva de la relación del hombre con la naturaleza.

Lo anterior es conocido. Pero, ¿acaso no está involucrado con la forma en que se hace, se desarrolla y se practica la recreación y la educación física? ¿Acaso los núcleos que propone la educación física como fundamentos de su estudio (por ejemplo, el cuerpo, la educación y el movimiento) o los de la recreación (ocio, tiempo libre y lúdica) pueden plantearse fuera del problema del poder que ha excluido todo saber venido de otros colectivos?

La recreación ha de plantearse abiertamente el problema a partir de la reivindicación de esos otros saberes. Por ese motivo, y teniendo en cuenta el inconveniente de exponer otras lógicas desde la nuestra, se presenta como una oportunidad los planteamientos de la tendencia culturalista, en cuanto cuestiona la imposición del saber del observador y procura una legitimidad de los discursos del otro.

\section{El hecho histórico social recreativo: el despertar de la cultura}

La propuesta contempla las posibilidades de escucha de otras voces que han sido acalladas pero que, de forma casi intangible, han hecho eco en algunas costumbres 
cotidianas. Es decir, no hemos escuchado nuestra propia voz. Sin entrar en profundos debates sobre el término cultura, y entendiéndola como un conjunto de representaciones sociales, hemos de partir de premisas fundamentales que no se determinen obligatoriamente por alguna tendencia acerca del saber.

En primer lugar, es necesario afirmar que existe diversidad de culturas; por lo tanto, hay diversidad de saberes que pueden ser igualmente valiosos para la construcción del conocimiento a partir de nuestros propósitos académicos, en este caso, la estructuración de la recreación como disciplina.

En segundo lugar, tal proceso de construcción de conocimiento debe ser vinculado con factores sociales concretos, es decir, sea cual sea el concepto de nación, Colombia tiene una situación de pobreza y hambre de una gran magnitud $y$, reconociendo la imposibilidad de plantear un saber neutro, los procesos para llegar a éste han de ser honestos y coherentes con dicha realidad.

Grimson afirma que "la cultura es histórica y ninguna sociedad puede comprenderse sin atender a su historicidad, a sus transformaciones" (2000: 24). Desde este punto de vista la recreación ha de revisar la existencia de experiencias históricas compartidas y la forma en que sus estructuras confluyen en tradiciones, hábitos y costumbres en la actualidad. "La interculturalidad incluye dimensiones cotidianas, a veces personales, de extrañamiento frente a la alteridad, desigualdades sociales, así como dimensiones políticas, grupales y estatales, de reconocimiento e igualdad", (Ibíd., 2000: 16), en este sentido, no solo se reconoce la existencia de fuentes de saber atadas a sus propias realidades, sino que se busca concretar esas lógicas diversas en espacios de producción de saberes.

Una de las maneras de resolver la paradoja en que nos envolvemos al intentar descifrar otras formas de co- nocimiento (una racionalidad que ha aparecido históricamente como única), es abrir la reflexión sobre el lenguaje, dentro de las posibilidades de interlocución entre diversas culturas. Es importante desdibujar los límites entre oralidad y literacidad, de manera que la comprensión no sólo se ubique en los discursos, sino en diversos modos de significación, tal como se presenta en la interpretación diversa del tiempo o del espacio vital. En otras palabras, ya no se trata sólo de que prime lo que se hace o lo que se dice (tal como lo plantea el estructuralismo o el idealismo), sino la búsqueda de otros puntos de referencia que, por supuesto, desbordan presupuestos occidentales y pueden generarse en experiencias de armonía con el entorno.

¿Cómo es, entonces, el conocimiento de la diversidad que responde a una estructuración investigativa coherente, y a problemas concretos de un contexto común? Aunque no es posible hacer afirmaciones definitivas y absolutamente certeras, podemos acercarnos a algunas características que, a partir de la perspectiva histórico social, den cuenta de la posibilidad de construcción propuesta:

a. El saber recreativo se legitima en el diálogo, incluyendo en los procesos de comunicación la sensibilización hacia la experiencia del otro.

b. El saber recreativo puede también ser construcción diferente del disciplinamiento científico, que nuestro medio se puede reconocer como tal. Es decir, ha de contener elementos que no encajan en las explicaciones lógico-racionales y pertenecen al mundo de los ritos, la espiritualidad o el arte.

c. Corresponde a una discusión permanente sobre modelos ideológicos, políticos y económicos que afectan un contexto común. Casi inevitablemente tienden a la resistencia ante procesos de homogenización de comportamientos o sensibilidades.

\section{Bibliografía}

BAJTIN, Mijail. (1997). Hacia una filosofía del acto ético. De los borradores y otros escritos. Barcelona, Anthropos.

BLOCH, Marc. (2001). El oficio del historiador. México. Fondo de Cultura Económica.

CARREÑO, Juan. (2003). ¿ Por qué neonarrar? Ponencia. En Memorias, X Congreso Internacional de Filosofía Latinoamericana, Bogotá, Universidad Santo Tomás. 
GARZÓN, Luis Alfonso et al. (2004). Programa curricular Licenciatura en Recreación, (documento de circulación interna, inédito), Bogotá. Universidad Pedagógica Nacional.

GRIMSON, Alejandro. (2000). Interculturalidad y comunicación. Bogotá. Norma.

PRIETO, Hernán. (2002). Resistir a la administración total de la vida, Bogotá. Universidad del Bosque.

\section{Notas}

1 Vale la pena anotar que en cuanto al currículo, propuestas como las de la Universidad Pedagógica Nacional (PCLEF 20009 se estructuran referentes culturales y sociales que critican y superan el carácter mecanicista y filsologista tradicional.
TURNER, Bryan. (1989). El cuerpo y la sociedad. México. Fondo de Cultura Económica.

VARGAS GUILLÉN, Germán. (2003). Fenomenología del ser y del lenguaje. Bogotá. Alejandría.

(1998). Investigaciones epistemológicas, Bogotá. Tecné.

VICH, Victor y ZAVALA, Virginia. (2004). Oralidad $y$ poder. Bogotá. Norma. 